\title{
Determination of Essential Amino Acids in Pangasius bocourti
}

Danuwat P, Rimruthai P, Phattanawan C and Peerarat D*

Institute of Product Quality and Standardization, Maejo University, Nonghan, Sansai, Chiang Mai, Thailand

\begin{abstract}
The purpose of this research was to analyze for the determination of essential amino acid in Pangasius bocourti which was aged between1-12 months. Essential amino acid were extracting by $6 \mathrm{M}$ hydrochloric acid $(\mathrm{HCl})$ using the EZ-Fast technology technique and afterwards the quality and quantity was analyzed by using the GC-MS. The highest amounts of essential amino acid were found in Pangasius bocourti aged 1 month. The highest quantities of essential amino acids were Lysine $8.41 \%$ and Leucine 8.30\%. Other essential amino acid such as Phenylalanine, Methionine, Isoleucine and Tryptophan were found at $4.54 \%$, $4.35 \%$, $4.25 \%$ and $2.36 \%$ respectively. In month 9, Threonine and Histidine were found at the highest amounts of essential amino acid, this was $5.85 \%$ and $2.96 \%$, respectively. Valine had the highest amounts at 7 months and 15 days for $6.79 \%$.
\end{abstract}

Keywords: Catfish; Essential amino acids; Extracting; EZ-Fasst; GCMS; Pangasius bocourti

\section{Introduction}

Essential amino acids are amino acids that cannot be synthesized by organism. There is need to obtain these amino acids by consuming food which contain them. The essential amino acids that cannot be synthesized are Isoleucine, Leucine, Lysine, Methionine, Phenylalanine, Threonine, Tryptophan and Valine. In infants, there are addition 2 essential amino acids which are Arginine and Histidine. Amino acids are important in the chemical composition of fish. They are the critical component of proteins in the fish body, which help increase the growth rate. Pangasius bocourti or Mekong catfish is one of the important species for cage culture in the Mekong river basin, especially Vietnam and Thailand $[1,2]$. Recently, the market of Pangasius frozen fillets has been increasing due to its white tender meat, low-fat content and easily digestible protein [3]. The Pangasius fish production was estimated at approximately 1.1 million tons in 2010 [4]. The purpose of this study was to analyze the quantities of essential amino acids in Pangasius bocourti, comparison between fish aged 1-12 months. The data will be used to provide basic information about fish nutrition and to promote as the distinctive point for pangasius fish market. The data obtained will also be important for the consumers, as they can obtain sufficient essential amino acids through consumption of Pangasius bocourti fish containing these amino acids.

\section{Materials and Methods}

\section{Materials}

Pangasius fish was raised in two net cages. The first net cages were used to culture the Pangasius fish aged 1-6 month and also other selected fish that had similar weight and size which had been measured before released into the water. In month 7 , the fish were moved to other net cages. Samples of the fish were collected every 15 days until they reached 12 months. Samples were stored in freezer before being extracted.

\section{Extraction of the amino acids from Pangasius bocourti}

Fish samples were chopped into small pieces and homogenized by using Homogenizer. After that, samples were dried in a freeze dryer. The dry fish meats were grounded into powder and kept in desiccators [5]. Samples were extracted by using Hydrochloric acid $6 \mathrm{M}$ and Thioglycolic acid $4 \%$ at a ratio of 1:1:1 (fish powder : $\mathrm{HCl}$ : Thioglycolic acid). Stirring continued in a shaking water bath at $50^{\circ} \mathrm{C}$ for 20 minutes.
The samples were kept in a hot air oven at $110^{\circ} \mathrm{C}$ for 22 hours. The solids and liquids phase were separated with centrifuges at $1,300 \mathrm{rpm}$ for 20 minutes [6-9]. The remaining liquids were collected, this aqueous was used in extracted amino acid by extracting kit: EZ-Faast $[6,10]$.

\section{Derivatization}

The amino acid analysis kit, EZ-Faast, was used to extract the amino acid. The liquid sample $(100 \mu \mathrm{L})$ was mixed with $200 \mu \mathrm{L}$ of sodium carbonate solution in a test tube. The sorbent tip was used to collect upper phase; eluting was added as a medium (sodium hydroxide and $\mathrm{N}$-propanol, 3:2) $200 \mu \mathrm{L}$ and rinse with $0.6 \mathrm{~mL}$ syringe. Reagent 4 (Isooctane) in $50 \mu \mathrm{L}$ and reagent 5 in (Iso-octane) $100 \mu \mathrm{L}$ were added and shaken to allow the phases to separate. The upper phase was collected then evaporated in Nitrogen-evaporator. Reagent 6 (Iso-octane $80 \%$ and Chloroform 20\%) was added to final sample in $100 \mu \mathrm{L}$ before being injected into the GC-MS.

\section{GC-MS}

The column of EZ: Faast GC with $10 \mathrm{~m}$ length and $0.25 \mathrm{~m}$ diameter was used in this study. The oven temperature was initially set at $110^{\circ} \mathrm{C}$ and programmed to $320^{\circ} \mathrm{C}$ at $30^{\circ} \mathrm{C} / \mathrm{min}$ for $1 \mathrm{~min}$. The gas carrier $(\mathrm{He})$ flow was constant at $1.1 \mathrm{~mL} / \mathrm{min}$. The injection volume was $2.5 \mu \mathrm{L}$ in split less mode. Injector and transferred temperature were $250^{\circ} \mathrm{C}$. All samples were injected into the GC-MS and then analyzed for $8 \mathrm{~min}$.

\section{Results and Discussion}

Figure 1 showed the chromatogram of the essential amino acids from pangasius fish, compared with standard essential amino acids (Figure 2). The Pangasius fish contained 9 essential amino acids; Valine, Leucine, Isoleucine, Threonine, Methionine, Phenylalanine, Lysine,

*Corresponding author: Peerarat D, Institute of Product Quality and Standardization, Maejo University, Nonghan, Sansai, Chiang Mai, Thailand, Tel: +66-918592389; E-mail: peeraratdoungtip@gmail.com

Received December 11, 2015; Accepted January 04, 2016; Published January 11,2016

Citation: Danuwat P, Rimruthai P, Phattanawan C, Peerarat D (2016) Determination of Essential Amino Acids in Pangasius bocourti. J Food Process Technol 7: 552. doi:10.4172/2157-7110.1000552

Copyright: @ 2016 Danuwat $\mathrm{P}$, et al. This is an open-access article distributed under the terms of the Creative Commons Attribution License, which permits unrestricted use, distribution, and reproduction in any medium, provided the original author and source are credited. 
Citation: Danuwat P, Rimruthai P, Phattanawan C, Peerarat D (2016) Determination of Essential Amino Acids in Pangasius bocourti. J Food Process Technol 7: 552. doi:10.4172/2157-7110.1000552

Page 2 of 4

Histidine and Tryptophan. Quantitative results of essential amino acid are shown in Table 1. Percentage values of essential amino acid among fish groups were significantly different $(\mathrm{p}<0.05)$. The data were plotted in linear graphs as divided in type of amino acid (Figures 3-11).

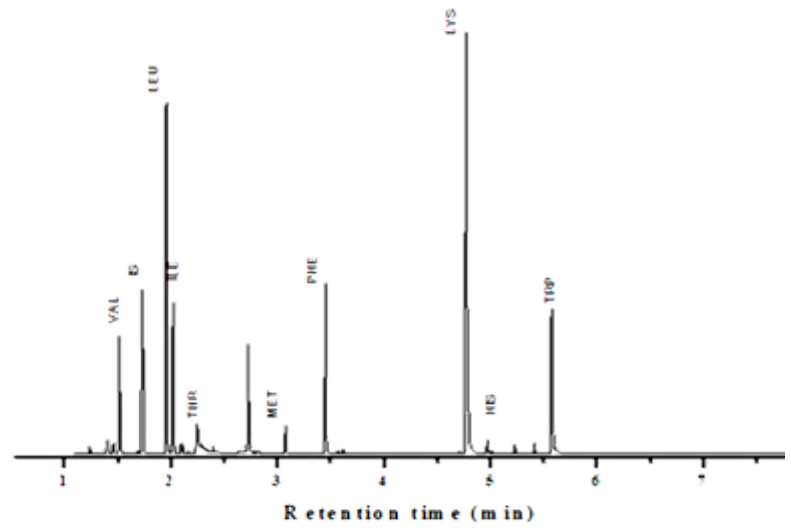

Figure 1: Chromatogram of the essential amino acids in Pangasius boucourti.

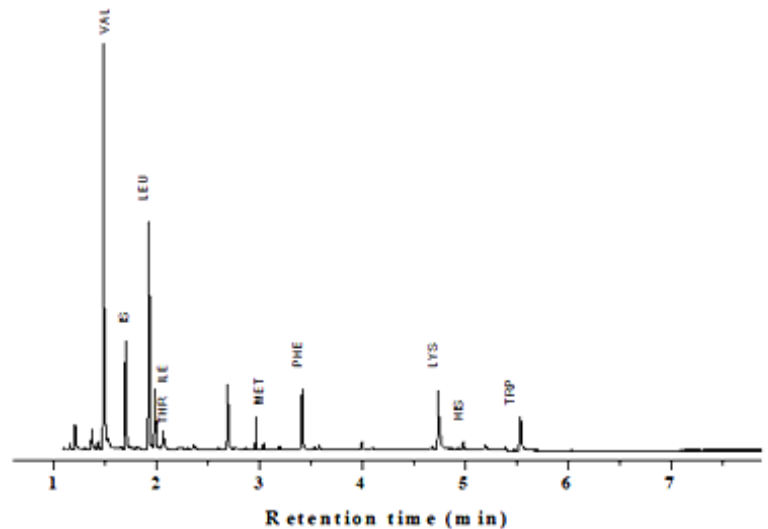

Figure 2: Chromatogram of standard essential amino acids

\begin{tabular}{|c|c|c|c|c|c|c|c|c|c|}
\hline Month & Valine & Leucine & Isoleucine & Threonine & Methionine & Phenylalanine & Lysine & Histidine & Tryptophan \\
\hline 1 & $4.63 \pm 0.03^{d}$ & $8.30 \pm 0.03^{a}$ & $4.25 \pm 0.04^{\mathrm{a}}$ & $2.63 \pm 0.14^{\mathrm{mn}}$ & $4.35 \pm 0.03^{a}$ & $4.53 \pm 0.37^{a}$ & $8.41 \pm 0.06^{a}$ & $2.78 \pm 0.07^{a b c}$ & $2.36 \pm 0.26^{a}$ \\
\hline 1.5 & $2.86 \pm 0.07^{g h}$ & $4.29 \pm 0.04^{\mathrm{jk}}$ & $3.04 \pm 0.04^{\mathrm{e}}$ & $3.21 \pm 0.05^{j}$ & $2.69 \pm 0.03^{c d}$ & $2.46 \pm 0.15^{\mathrm{ef}}$ & $4.46 \pm 0.05^{\mathrm{fg}}$ & $2.58 \pm 0.03^{\text {defg }}$ & $2.02 \pm 0.01^{\mathrm{bc}}$ \\
\hline 2 & $2.88 \pm 0.10^{g h}$ & $4.32 \pm 0.07^{\mathrm{jk}}$ & $2.57 \pm 0.02^{\mathrm{jkl}}$ & $2.71 \pm 0.03^{\mathrm{m}}$ & $2.55 \pm 0.09^{e}$ & $2.26 \pm 0.01^{g h}$ & $3.90 \pm 0.04^{h}$ & $2.47 \pm 0.06^{\mathrm{fghi}}$ & $2.00 \pm 0.02^{c}$ \\
\hline 2.5 & $3.16 \pm 0.04^{\mathrm{fg}}$ & $5.12 \pm 0.08^{e}$ & $2.75 \pm 0.10^{g h}$ & $3.58 \pm 0.14^{g h}$ & $2.71 \pm 0.16^{\mathrm{cd}}$ & $2.66 \pm 0.03^{c}$ & $4.51 \pm 0.11^{f}$ & $2.82 \pm 0.12^{\mathrm{ab}}$ & $2.03 \pm 0.00^{\mathrm{bc}}$ \\
\hline 3 & $2.76 \pm 0.40^{g h}$ & $5.44 \pm 0.17^{d}$ & $2.54 \pm 0.01^{\mathrm{klm}}$ & $3.34 \pm 0.03^{i}$ & $2.77 \pm 0.12^{c}$ & $2.33 \pm 0.02^{\mathrm{g}}$ & $4.50 \pm 0.04^{f}$ & $2.50 \pm 0.10^{\mathrm{fghi}}$ & $1.99 \pm 0.00^{c}$ \\
\hline 3.5 & $3.38 \pm 0.50^{\text {ef }}$ & $4.27 \pm 0.09^{j k}$ & $2.57 \pm 0.01^{1 \mathrm{kl}}$ & $3.53 \pm 0.02^{\mathrm{h}}$ & $2.64 \pm 0.16^{d}$ & $2.30 \pm 0.01^{g}$ & $4.38 \pm 0.05^{\mathrm{g}}$ & $2.65 \pm 0.11^{\text {bcdef }}$ & $2.00 \pm 0.01^{c}$ \\
\hline 4 & $3.62 \pm 0.34^{e}$ & $5.02 \pm 0.07^{f}$ & $2.81 \pm 0.06^{\mathrm{fg}}$ & $3.65 \pm 0.2^{g}$ & $2.56 \pm 0.08^{e}$ & $2.46 \pm 0.03^{\mathrm{ef}}$ & $3.74 \pm 0.12^{i}$ & $2.54 \pm 0.04^{\text {efgh }}$ & $2.05 \pm 0.02^{\mathrm{bc}}$ \\
\hline 4.5 & $2.75 \pm 0.01^{\mathrm{gh}}$ & $4.07 \pm 0.01^{1 \mathrm{~m}}$ & $2.49 \pm 0.01^{\mathrm{mn}}$ & $2.63 \pm 0.08^{m n}$ & $2.43 \pm 0.02^{\mathrm{gh}}$ & $2.07 \pm 0.04^{i j}$ & $3.18 \pm 0.06^{n}$ & $2.36 \pm 0.02^{\mathrm{hi}}$ & $1.99 \pm 0.01^{c}$ \\
\hline 5 & $4.56 \pm 1.39^{d}$ & $4.75 \pm 0.10^{\mathrm{h}}$ & $2.76 \pm 0.02^{\mathrm{g}}$ & $3.87 \pm 0.08^{e}$ & $2.51 \pm 0.07^{\text {efg }}$ & $2.26 \pm 0.05^{\mathrm{gh}}$ & $3.94 \pm 0.01^{\mathrm{h}}$ & $2.72 \pm 0.04^{\text {bcde }}$ & $2.01 \pm 0.02^{\mathrm{bc}}$ \\
\hline 5.5 & $3.19 \pm 0.20^{f g}$ & $4.91 \pm 0.07^{g}$ & $2.76 \pm 0.10^{g}$ & $3.77 \pm 0.07^{f}$ & $2.43 \pm 0.01^{\mathrm{gh}}$ & $2.17 \pm 0.07^{\mathrm{hi}}$ & $5.02 \pm 0.16^{c}$ & $2.59 \pm 0.08^{\text {cdefg }}$ & $2.01 \pm 0.01^{b c}$ \\
\hline 6 & $2.69 \pm 0.08^{\mathrm{h}}$ & $4.01 \pm 0.04^{\mathrm{m}}$ & $2.45 \pm 0.02^{n}$ & $3.36 \pm 0.03^{i}$ & $2.43 \pm 0.01^{\mathrm{gh}}$ & $2.09 \pm 0.01^{i j}$ & $3.31 \pm 0.06^{\mathrm{m}}$ & $2.45 \pm 0.03^{\text {fghi }}$ & $1.99 \pm 0.01^{c}$ \\
\hline 6.5 & $3.12 \pm 0.26^{\mathrm{fgh}}$ & $4.34 \pm 0.02^{j}$ & $2.85 \pm 0.03^{f}$ & $4.68 \pm 0.05^{c}$ & $2.70 \pm 0.09^{c d}$ & $2.64 \pm 0.03^{c d}$ & $5.95 \pm 0.06^{b}$ & $2.48 \pm 0.05^{\text {fghi }}$ & $2.04 \pm 0.01^{b c}$ \\
\hline 7 & $5.64 \pm 0.07^{b}$ & $4.12 \pm 0.06^{\prime}$ & $3.50 \pm 0.10^{c}$ & $4.67 \pm 0.18^{c}$ & $2.94 \pm 0.07^{b}$ & $2.80 \pm 0.05^{b}$ & $3.41 \pm 0.14$ & $2.57 \pm 0.18^{\text {efgh }}$ & $2.02 \pm 0.02^{\mathrm{bc}}$ \\
\hline 7.5 & $6.79 \pm 0.06^{a}$ & $6.18 \pm 0.04^{b}$ & $3.66 \pm 0.02^{b}$ & $5.73 \pm 0.06^{b}$ & $2.66 \pm 0.012^{d}$ & $2.74 \pm 0.13^{\mathrm{bc}}$ & $4.92 \pm 0.08^{d}$ & $2.55 \pm 0.04^{\text {efgh }}$ & $2.04 \pm 0.02^{\mathrm{bc}}$ \\
\hline
\end{tabular}

${ }^{*}$ Mean $\pm S D$ in the same column with different superscript letters are significant differences $(p<0.05)$

Table 1: Content of essential amino acid in Pangarius boucourti (1-12 months)
Figure 3 percentage of Valine was significantly different $(\mathrm{p}<0.05)$. It was found highest in fish aged 7.5 month with $6.79 \%$. Fish aged 7 month and 8 month also had high quantities of Valine at $5.64 \%$ and 5.14\%. However, after 7.5 month, percentage of Valine was slightly decreased and remained stable when fish aged 9 month and 15 days. As showed in figures 4-8, Pangasius fish in aged 1 month had the most highest of Leucine, Isoleucine, Methionine, Phenylalanine and Lysine with respective $8.30 \% 4.25 \% 4.35 \% 4.53 \%$ and $8.41 \%$. Threonine was found at the highest level when aged 9 months, 5.85\%. Fish aged 7.5 month also had high Threonine with $5.73 \%$. But they were significantly different $(\mathrm{p}<0.05)$ in mean value of amino acid percentage (Figure 9$)$ The quantity of Histidine was the same as Threonine, it was found at its highest level in fish aged 9 month, approximately $2.96 \%$. In addition, Histidine values were high in fish 2.5, 10 and 1 month with 2.81\% 2.81\% and $2.78 \%$ respectively (Figure 10). Tryptophan was different from the other amino acid. It appeared that between 1-12 months, they were not significantly different in mean values of amino acid ( $\mathrm{p} \geq 0.05)$, except for the first month of the fish. It has high percentage of Tryptophan (Figure 11) but after the second month, the amino acid remained at a steady level. Amino acid values were changed but none of them were lost during the experimental period. The highest percentage of Valine was found in fish aged 7.5 month with $6.79 \%$. The highest amounts of Leucine, Isoleucine, Methionine, Phenylalanine and Lysine were found in fish aged 1 month with $8.30 \%, 4.25 \%, 4.35 \%, 4.53 \%$ and $8.41 \%$ respectively. It appeared that most of the essential amino acid was found in young fish. But 1 month old fish were not appropriated for extracting the amino acids due to the fish size and economical reason. They were too small and inconvenient when preparing samples. The recommended aged of pangasius fish should be around 7-8 months because they had high amino acid after the first month. However, Threonine and Histidine were found at the highest level in fish aged 9 month with $5.73 \%$ and $2.96 \%$, respectively. The percentage of Tryptophan was not significantly different $(\mathrm{p} \geq 0.05)$ during $1-12$ month. It stayed at a steady level during the experimental period.

Quantities of the essential amino acid in pangasius fish depend on 


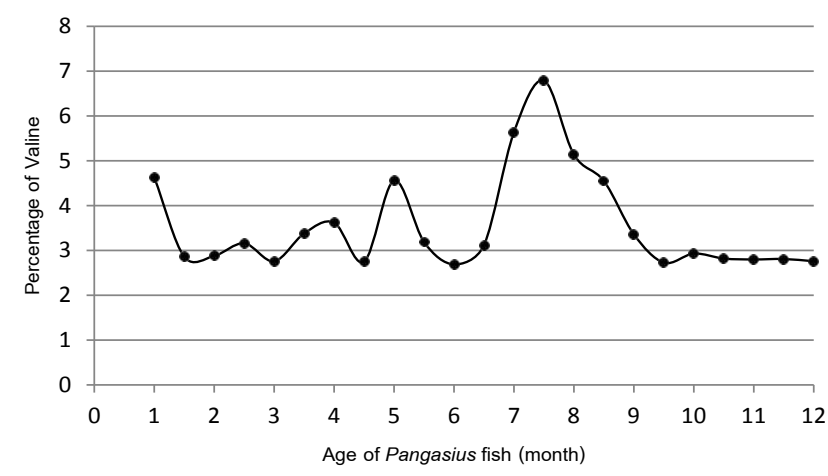

Figure 3: Valine content in Pangasius boucourti between 1-12 months.

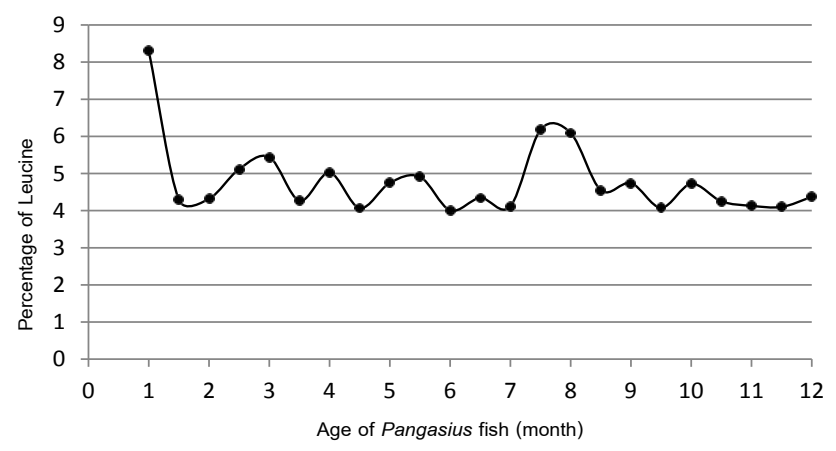

Figure 4: Leucine content in Pangasius boucourti between 1-12 months.



Figure 5: Isoleucine content in Pangasius boucourti between 1-12 months.

many factors such as fish diet. This is because they cannot synthesize the essential amino acid by themselves, fish also need amino acid through foods too. Now-a-days, supplement fish diet products are popular in fisheries industry. Amino acid in fish diet should be adequate and appropriate for fish. It has an influence towards the fish's growth rate. Fish that are feeding by nutritive diet will grow faster in a shorter period and it will be beneficial to the export industry. For recommendation, this study should observe requirement of amino acid in fish by feeding them with purified diet or semi purified diet to control the nutrition balance [11] and in addition the quantities of amino acid in fish diet should be analyzed to control growth rate.

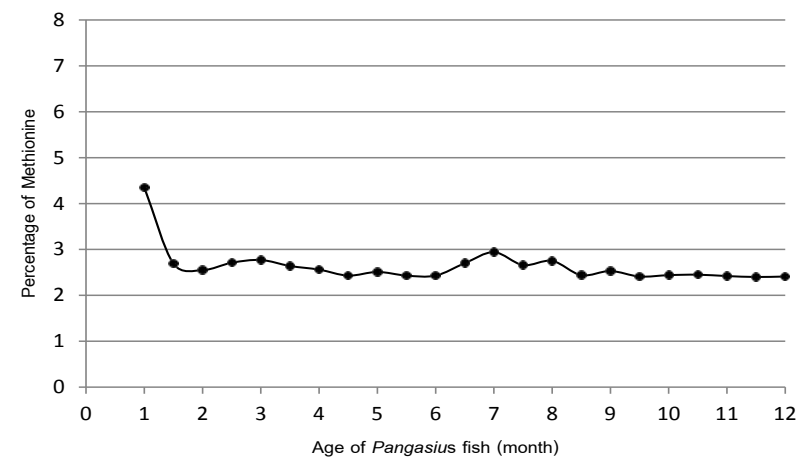

Figure 6: Methionine content in Pangasius boucourti between 1-12 months.

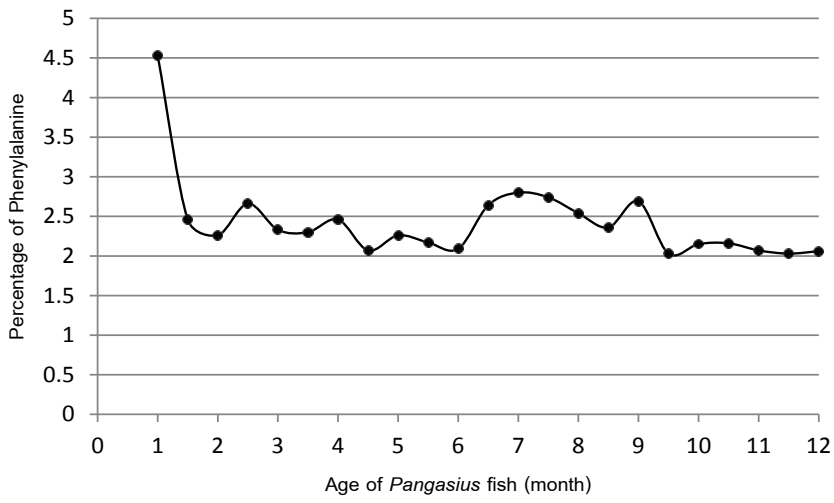

Figure 7: Phenylalanine content in Pangasius boucourti between 1-12 months.



Figure 8: Lysine content in Pangasius boucourti between 1-12 months.

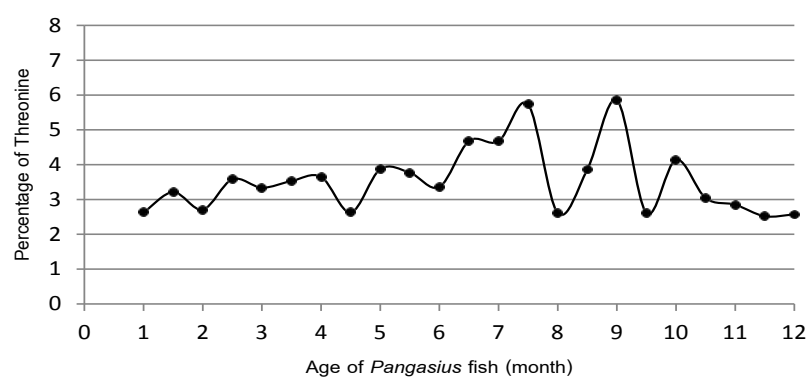

Figure 9: Threonine content in pangasius boucourti between 1-12 months. 


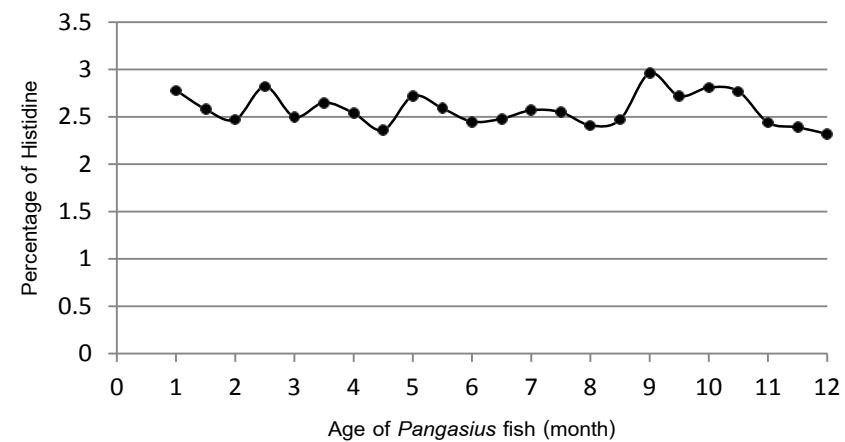

Figure 10: Histidine content in Pangasius boucourti between 1-12 months.

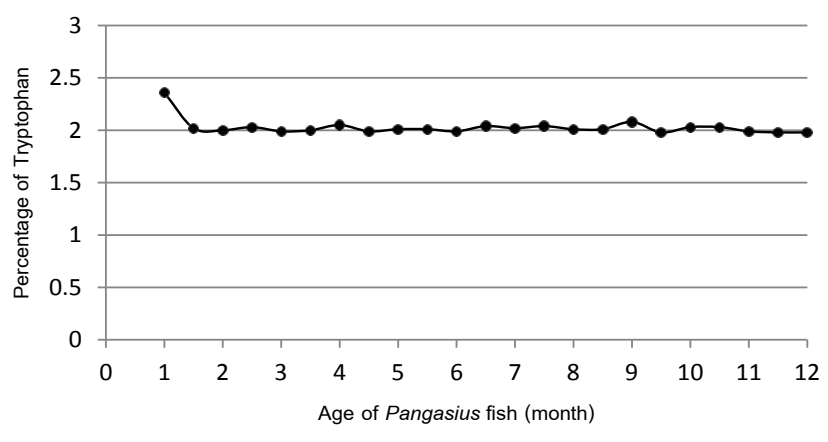

Figure 11: Tryptophan content in Pangasius boucourti between 1-12 months.

\section{Conclusion}

Pangasius bocourti, aged between 1-12 months, were containing 9 types of amino acids: Valine, Leucine, Isoleucine, Threonine, Methionine,
Phenylalanine, Lysine, Histidine and Tryptophan. Pangasius fish aged 1 month have the highest amount of Lysine, Leucine, Phenylalanine, Methionine, Isoleucine and Tryptophan. Threonine and Histidine are highest in fish 9 month and Valine is highest in fish 7 month. However, the appropriate age of pangasius fish for extraction of essential amino acids should be around 7-8 months.

\section{Acknowledgements}

The authors wish to thank the National Food Institute (NFI) of Thailand for the financial support.

\section{References}

1. Jiwyam W (2010) Growth and Compensatory Growth of Juvenile Pangasius bocourti Sauvage, 1880 relative to ration. Aquaculture 306: 393-397.

2. Cacot $P$, Legendre M, Dan TQ, Tung LT, Liem PT, et al. (2002) Induced Ovulation of Pangasius. Aquaculture 213: 199-206.

3. Thammapat $P$, Raviyan $P$, Siriamornpun S (2010) Proximate and Fatty Acids Composition of the Muscles and Viscera of Asian Catfish (Pangasius bocourti). Food Chemistry 122: 223-227.

4. Van DH, Doolgindachbaporn S, Suksri A (2014) Effect of Low Molecular Weight agar an Lactobacillus plantarum on Growth Performance, Immunity and Disease Resistance of Basa fish (Pangasius bocouti, Sauvage 1880). Fish\&Shellfish Immunology 41: 340-345.

5. AOAC (2005) Official Methods of Analysis. Association of Official Analytical Chemists. Washington DC

6. Mustafa A, Aman P, Anderson R, Kamal-Eldin A (2007) Analysis of Free Amino Acids in Cereal Products. Food Chemistry 105: 317-324.

7. Fountoulakis M, Lahm HW (1998) Hydrolysis and amino acid composition of proteins. J Chromatogr A 826: 109-134.

8. Xian Z, Chao Z, Liang Z, Hongbin C (2008) Amino Acids Production from Fish Proteins Hydrolysis in Subcritical Water. Chinese Journal of Chemical Engineering 16: 456-460.

9. Usydus Z, Szlinder-Richert J, Adamczyk M (2009) Protein Quality and Amino Acid Profiles of Fish products available in Poland. Food Chemistry 112: 139145.

10. Phenomenex (2001) EZ-Faast Easy-fast Amino Acid Sample Testing Kit Manual. Torrance, Phenomenex, CA, USA.

11. Tantikitti C, Chimsung N (2001) Dietary Lysine Requirement of Fresh Water Catfish (Mystus nemurus Cuv. \& Val.). Aquaculture Research 32: 135-141. 